\title{
Flood risk and climate change in the Rotterdam area, The Netherlands: enhancing citizen's climate risk perceptions and prevention responses despite skepticism
}

\author{
Joop de Boer ${ }^{1}$ W. J. Wouter Botzen ${ }^{1}$ Teun Terpstra ${ }^{2}$
}

Received: 21 March 2015/Accepted: 13 November 2015/Published online: 12 December 2015

(C) The Author(s) 2015. This article is published with open access at Springerlink.com

\begin{abstract}
Effective communication about climate change and related risks is complicated by the polarization between "climate alarmists" and "skeptics." This paper provides insights for the design of climate risk communication strategies by examining how the interplay between climate change and flood risk communication affects citizens' risk perceptions and responses. The study is situated in a delta area with substantial geographic variations in the occurrence and potential impact of flood risk, which has led to initiatives to make the area more "climate proof." We developed a research model that examines individual differences in processing information about climate change related flood risk, based on the postulate that individuals often make an implicit trade-off between motivation to know "what is real" and motivation to maintain prior beliefs. A field experiment, embedded in a survey $(n=1887)$, sought to test out how the participants responded to risk frames in which a story on flood was either or not combined with climate change information.
\end{abstract}

Editor: Christopher Reyer.

Electronic supplementary material The online version of this article (doi:10.1007/s10113-015-0900-4) contains supplementary material, which is available to authorized users.

Joop de Boer
joop.de.boer@vu.nl
W. J. Wouter Botzen
wouter.botzen@vu.nl
Teun Terpstra
t.terpstra@hkv.nl
Institute for Environmental Studies, VU University, De
Boelelaan 1087, 1081 HV Amsterdam, The Netherlands
2 HKV Consultants, Lelystad, The Netherlands

The results show that it was possible to increase the participants' local climate risk perception in combination with increased motivation for flood damage prevention, despite a certain level of climate change skepticism. A general implication of our study is that relevant and diagnostic information about local climate-related flood risks can stimulate citizens' need to know "what's real" and their willingness to take responsibility for preparedness.

Keywords Climate change $\cdot$ Communication $\cdot$ Flood risk $\cdot$ Prevention $\cdot$ Risk perception $\cdot$ Skepticism

\section{Introduction}

Delta cities may be affected by a number of climate change impacts, including rising sea levels and property damage and casualties from extreme flood events (Dempsey and Fisher 2005; Jongman et al. 2012; Smit and Wandel 2006). A proactive approach to addressing these vulnerabilities requires timely investment in flood protection infrastructure and urban planning, as well as open and clear communication with the inhabitants about the risks they face (Moser 2010). As the local impacts of climate change are extremely difficult to predict (Berkhout et al. 2014), however, the intended communication may seriously be hampered by the polarization between "climate alarmists" and "skeptics" (Leiserowitz 2005; Whitmarsh 2011). In several Western countries, including the Netherlands, it has been found that almost half of the population agrees with the statement that "the seriousness of climate change has been exaggerated" (de Boer et al. 2013; Scruggs and Benegal 2012). This skepticism may work against open discussions on issues such as geographic variations in the occurrence and potential impact of flood risk (Fischhoff 2007). With 
regard to flood preparedness communications, some scholars even suspect that willingness to implement flood preparedness behaviors may be higher across political groups if the term "climate change" is omitted (de Bruin et al. 2014). Although several studies have been done on the background and impact of climate skepticism (e.g., Corner et al. 2012; Hart and Nisbet 2012), little research has directly examined how the interplay between climate change and flood risk communication affects citizens' perceptions and responses. The present paper, therefore, aims to address this gap, focusing on conditions that facilitate more accurate (versus biased) information processing. It describes an experiment carried out in the Rotterdam area of the Netherlands to increase both citizens' local climate risk perception and their motivation for flood damage prevention, despite a certain level of skepticism. The experiment was developed to support policy makers in the region with knowledge about communicating with inhabitants on these issues.

\section{Theoretical background}

In order to examine the interplay between climate change and flood risk communication, we developed a research model of the motivational conditions that can lead to individual differences in information processing (see Fig. 1). We will examine the effects of information conditions in the form of risk frames that tell a story about flooding in a local context. Our model postulates that, in the context of risk communication, an individual often makes an implicit trade-off between motivation to know "what is real" and motivation to maintain prior beliefs, before reaching a personal conclusion. In the model, the trade-off is affected by differences in individual's flood risk concerns and beliefs about climate change, which, in turn, are affected by the frame of the communication. This makes it important for communicators to know how to frame their story about risk in a way that facilitates accurate information processing. Evidence for the model's concepts and their relationships to one another is described below.
From a psychological and cultural perspective, the concept of frame refers to mental knowledge structures that capture the typical features of a situation or an event (e.g., a disaster) to promote a coherent understanding (Barsalou 1992; Bednarek 2005). Frames are based on a shared cultural background of experiences, beliefs and practices, which can often be created by or reflected in the language. A coherent understanding of "risk" requires, in the words of the linguists Fillmore and Atkins (1992), a risk frame, which crucially involves the notions of chance and harm, woven into a story about particular events (e.g., extreme weather) that are conceptually linked to an unwelcome outcome (e.g., a flood). Risk frames that are intended to facilitate accurate information processing should capture the typical features of the issue in a way that is easy to understand and enables individuals to focus attention on the most relevant and diagnostic information (i.e., information that is useful for making sound personal risk management decisions). However, the frame of a complex event and the content associated with this frame can affect motivational concerns and prior beliefs in ways that may, on the one hand, support accurate information processing and, on the other hand, lead to biases and errors in judgment.

The postulate that an individual often makes an implicit trade-off between motivation to know "what is real" and motivation to maintain prior beliefs is a specific instance of a more general process, described by scholars in the field of judgment and decision making (Darke and Chaiken 2005; Hart et al. 2009; Kunda 1990; Molden and Higgins 2005). These scholars consider two broad classes of motivational influences on information processing; the first involves people's desires for reaching a specific conclusion in their judgments, and the second involves their desires to use certain types of strategies while forming their judgments (Molden and Higgins 2005). The influence of desires for reaching a specific conclusion is a typical example of biased information processing. Desires to use particular types of strategies include an individual's motivation to reach an accurate conclusion. Generally, as Higgins (2012, p. 105) notes, establishing "what's real" is one of the main
Fig. 1 Research model of individual differences in information processing
Information condition Individual differences in information processing Effect

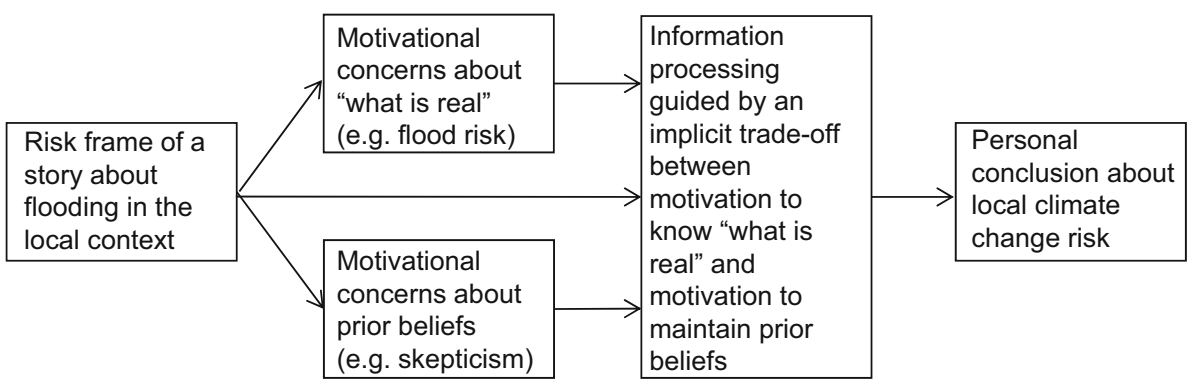


things that people want, even if the process of establishing "what's real" is painful. However, an individual can also be motivated to hold and maintain attitudes and beliefs that have positive implications for the self (Darke and Chaiken 2005; Hart et al. 2009). When people are confronted with arguments that challenge an important attitude, the relevance of the issue to their enduring values can lead to more self-protective processing, which is not unbiased but enables them to defend their initial position (Johnson and Eagly 1989). Hence, the latter process is largely guided by motivation to maintain prior beliefs.

The motivational impact of flood risk concerns depends on two higher-order systems of motivation, termed promotion and prevention, which are conceived as distinct but not bipolar constructs (Higgins 1997, 2000, 2012). Promotion concerns make an individual sensitive to positive outcomes and hits (as opposed to errors) that may be gained through aspirations, accomplishments and ideals. In contrast, prevention concerns make an individual sensitive to negative outcomes and errors that have to be avoided by fulfilling one's obligations and responsibilities. Individuals can be chronically more promotion or prevention oriented but their momentary focus on promotion or prevention will also depend on the situation, which may be framed in such a way that either promotion or prevention aspects are highlighted. Hence, establishing "what's real" is affected by an emphasis on information processing that is either eager (accurate not to miss gains) or vigilant (accurate to avoid losses). Vigilant strategies may be particularly relevant for information processing related to climate change and flood risk, because these strategies fit best into an individual's prevention-focused concerns about safety and safety-related responsibilities, which are likely to be evoked by an awareness of this type of risk (Zhou and Pham 2004).

The motivational impact of prior beliefs is related to the difference between general messages (and beliefs) about climate change and specific messages (and beliefs) about climate change impacts at the local level (e.g., Leiserowitz 2005; Ruddell et al. 2012; Scannell and Gifford 2013; Whitmarsh 2008). General messages about the consequences of climate change, such as global sea level rise, may have implications for the cultural values of individuals who are skeptical, because they often have beliefs that support a free market ideology and downplay the importance of environmental issues (Heath and Gifford 2006; Kahan et al. 2011). This increases the likelihood of information processing guided by motivation to maintain prior beliefs (e.g., Corner et al. 2012; Hart and Nisbet 2012; Whitmarsh 2011). In contrast, the role of motivation to know "what is real" may increase if climate change information appears to be relevant for people's prevention concerns, but does not necessarily have negative implications for their self-views. An example are specific messages about impacts on flood risk in the context of local planning, which are not intended to be alarming but provide information about climate change that can be useful for decision making. Hence, according to the trade-off model, it may be possible to increase people's local climate risk perception in combination with increased motivation for flood damage prevention, despite a certain level of skepticism.

\section{Methods}

\section{Study area}

The experiment was carried out in the Rotterdam area of the Netherlands to support policy makers with knowledge about communicating with inhabitants on plans to make the area more "climate proof." Climate proofing aims to reduce the risks of flooding by "hard" infrastructure and "softer" measures, such as insurance schemes or evacuation plans, which require effective risk communication with the inhabitants (Kabat et al. 2005). The Rotterdam area is particularly suitable for this approach, as it is located at the mouth of the river Rhine and the river Meuse, near the North Sea coast. An overload of surface water due to extreme weather events can cause overland flooding and in house flooding in the whole or part of the area. The geographic variations are largely a result of differences in the development of dikes and polders. Polders are lowlying areas of reclaimed land (up to $7 \mathrm{~m}$ below sea level), which are protected by dikes, designed to withstand water levels that occur with frequencies of 1/10,000 per year or $1 / 4000$ per year. Along the river there are also city areas outside the dikes, such as redeveloped harbor areas, which are to a certain extent safeguarded against flooding due to their elevation above sea level (about $3 \mathrm{~m}$ ). Potential barriers to risk communication in this context are not only skepticism about the seriousness of climate change, but also a lack of awareness among the inhabitants of the geographic variations in the occurrence and potential impact of flood risks (Kokx and Spit 2012). Most of them lack direct experience with floods, which is a major factor to stimulate risk awareness and disaster preparedness (Botzen et al. 2009; Harvatt et al. 2011; Grothmann and Reusswig 2006; Kreibich et al. 2005, 2011; Siegrist and Gutscher 2006).

\section{Experimental design}

Embedded in a survey among a sample of inhabitants of the study area, several risk frames were used to examine the adequacy of the trade-off model and to predict local 
climate risk perception regarding particular locations. The locations chosen for this study were the city areas outside the dikes, which may be compared with neighborhoods in deep polders (see above). The sample was randomly divided into a control group and four framed groups. As we were not in the position to inform the inhabitants about flood risks associated with their own dwellings, we measured how the framed groups responded to descriptions of risks that had been contextualized in an area outside the dikes or in a deep polder. They were asked to respond as if they themselves lived in the specified neighborhood. This focal context of the risk was combined with a statement on its future direction, which either emphasized the uncertain effects of future climate change or the continuity of flood control protection by public authorities. The latter condition was included because Dutch policy makers often prefer to highlight flood control measures. In short, there were two factors (focal context and future direction of the risk), each with two levels, resulting in a $2 \times 2$ factorial design with one control group.

All the presented information was carefully chosen to provide descriptions, captured in a risk frame, which the local authorities could use for the purpose of climate change and flood risk communication. In addition to this basic structure, there were visual images of floor flooding and deep flooding, which can make climate change salient for many people (O'Neill et al. 2013). The continuity of flood control was also illustrated by photographs. The risk information was realistic in terms of flood frequency and depth. It referred to floor flooding outside the dikes (a 1-in-10-year probability of flooding with limited depth of inundation) or deep flooding in a deep polder (a 1-in2000-year probability of flooding with high depth of inundation).

Four variables were developed to assess the impacts of the experimental conditions; they were meant to measure prevention- and promotion-focused responses to the risk frames, skepticism about climate change, and local climate risk perception regarding areas outside the dikes (hereafter also called perceived outside-the-dikes risk). The control group was asked to respond to the survey questions on these topics with their own situation in mind. This group was meant to provide a reference level for comparison with the participants who responded to the risk frames. It was expected that the risk frames would lead to different levels of prevention-focused responses and perceived outside-thedikes risk, depending on the relevance of the diagnostic information to the judgments being made and motivationbased trade-offs. That is, we expected the highest levels of both prevention-focused responses and perceived outsidethe-dikes risk among those participants who were asked to imagine living outside the dikes and who were informed on the risk of floor flooding and the uncertain effects of future climate change (frame 1); we expected the lowest levels among those who were asked to imagine living in a deep polder and who were informed on the risk of deep flooding and the continuity of flood control protection by public authorities (frame 4). We also expected that preventionfocused responses would correlate positively with perceived outside-the-dikes risk among the participants in the "outside the dikes" conditions (frames 1 and 2) and that the prevention-focused responses of the others would be less strongly related to their perception of the risk outside the dikes. In all the conditions, negative correlations were expected between these variables and climate change skepticism as a result of motivation-based trade-offs. In view of the distinct (but not bipolar) orientations of prevention and promotion motivation, there were no expectations about an effect of the frames on promotion-focused responses. To explore the generalizability of the results, we included the descriptive variables gender, age, household size, level of education and residential location (i.e., urban, suburban or rural part of the Rotterdam area).

\section{Subjects and procedure}

The sample was drawn from a representative panel of persons in the Rotterdam area who were willing to participate in web-based research for a small reward (about $€$ 1.50 per person per $10 \mathrm{~min}$ ), which they could keep for themselves or donate to charity. To be eligible, participants had to meet the following criteria: they were between the ages of 25 until 75, were head of household, or the spouse/partner of the head of household, and therefore potentially responsible for the safety of themselves and any other members of their household. In June 2011, the questionnaires were completed by 1887 of the invited participants (response rate within the time frame $69 \%$ ), who had been randomly divided into four experimental groups (of about 400) and one control group (of about 200). The exact numbers of participants were $423,414,433,412$ and 205, respectively; $49 \%$ of the sample was female. The mean age was 50 years and $26 \%$ had a bachelor's or master's degree. The variables gender, age, household size, level of education and residential location did not differ between the five groups (Chi-square, $p \mathrm{~s}>.05$ ).

The framed groups and the control group received versions of the questionnaire that shared the same structure, with a brief description to introduce its topic ("living near major rivers"). Next, the framed groups were provided a storyline that was based on one of the risk frames. Figure 2 provides an overview of the design, the photographs and the key phrases that were used in each of the frames. The whole text is shown in Appendix 1 (see Electronic Supplementary material). Several blocks of questions measured prevention- and promotion-focused responses to the 


\section{Frame 1}

Focal context Living outside the dikes. Key phrases: "During times of high water levels streets can be covered with water. Such high water levels occur on average once in 10 years."

Future direction of the risk Changing climate. Key phrases: "Moreover, the climate is changing, which increases the amount of water in rivers and causes sea level rise. According

\section{Frame 3}

Focal context

Living in a deep polder.

Key phrases: "Dikes can breach if water levels in the river are very high. Such high water levels occur on average once in 2000 years. But, a dangerous situation can also arise if water levels are lower. That is because not all dikes are exactly equally strong. Even though the probability is low, the water level in the polder after a dike breach to experts, the Netherlands is insufficiently protected against the consequences of climate change. As a result, the flood risks (...) may increase in the future."

Pictures: Four photos of floor floods.

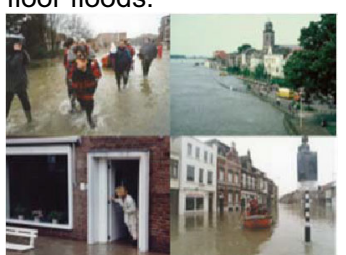

can rise up to 2 to 3 meters high."

Future direction of the risk

Changing climate.

Key phrases: See Frame 1. Pictures: Four photos of deep floods.

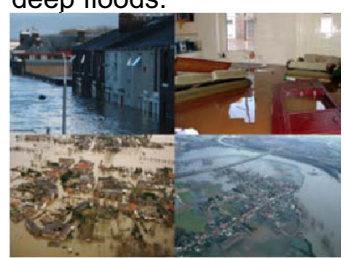

\section{Frame 2}

Focal context

Living outside the dikes.

Key phrases: See Frame 1.

Future direction of the risk

Continuous control. Key phrases: "Moreover, the government is continuously working on flood safety. Recently, a new Delta Committee has advised how the Netherlands can be protected against the water, also in the far future (until the year 2100)."
Pictures: Four photos of neighborhoods outside the dikes.

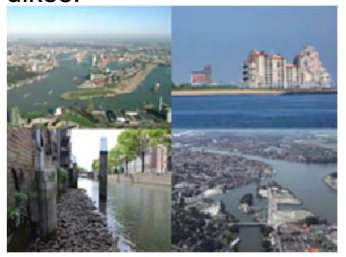

\section{Frame 4}

Focal context

Living in a deep polder.

Key phrases: See Frame 3.

Future direction of the risk

Continuous control.

Pictures: Four photos of Key phrases: See Frame 2. hard infrastructure for flood protection.

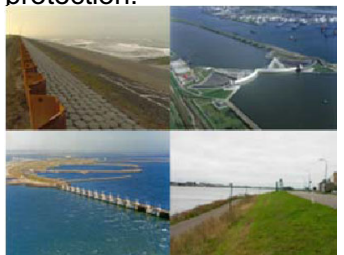

Fig. 2 Overview of the design, the photographs and the key phrases used in each of the frames

frames, monetary valuation of insurance against flood risk, perceptions of flood hazard adjustments, chronic prevention and promotion motivation, and beliefs about global and local impacts of climate change. The control group answered slightly differently worded questions with their own situation in mind. We pretested the questionnaire by means of face-to-face interviews and conducted a pilot study (not published) to check whether the participants were able to understand the descriptions and the questions, which were based on earlier work on these topics (e.g., Botzen and van den Bergh 2012; Terpstra and Lindell 2013). The results of the sections on the monetary valuation of insurance against flood risk (Botzen et al. 2013), chronic differences in motivation (de Boer et al. 2014), information need (Terpstra et al. 2014) and preparedness (de Boer et al. 2015) were described in separate papers. Here the focus is on the impacts of the risk frames and climate skepticism on prevention-focused responses and local climate risk perception regarding the area outside the dikes. Appendix 2 (see Electronic Supplementary material) presents the means and standard deviations of the relevant items.

\section{Measures}

Motivation for flood damage prevention was measured in terms of prevention-focused responses to the risk frames, which were examined together with promotion-focused responses. It should be noted, however, that this study gave relatively less attention to promotion motivation because prevention motivation may be of primary importance for flood risk communication. Building on Higgins's theory (Higgins 1997, 2012), the prevention-focused responses referred to vigilance ("If I lived in a neighborhood outside the dikes, I would become very agitated by images of high water levels"), loss avoidance ("I would fear that my property value will decrease"), defensive pessimism ("I would keep in mind that I will have to deal with flood damage sooner or later") and flood preparedness (e.g., "I would make sure that I am well prepared for high water levels"). All responses were invited on a seven-point scale. The questions for the control group were worded slightly different ("As inhabitant of this river delta, I want to make sure that I am well prepared for high water levels"). Cronbach's alpha of the four-item scale was .83. Three 
items reflected a promotion focus on potential gain (e.g., "If I lived in a neighborhood outside the dikes, then I think that my house will be very attractive because of the water abundant environment"). Cronbach's alpha of the threeitem scale was .63. Among the total group of participants, the two scales were almost uncorrelated $(r=-.07$, $p<.001, n=1887$ ).

A set of six items measured general beliefs about climate change and perceived climate-related risk in the area outside the dikes. The participants were invited to respond on a seven-point scale, ranging from completely disagree to completely agree. The key item for assessing climate skepticism ("The seriousness of climate change has been exaggerated") was used in several surveys (de Boer et al. 2013; Scruggs and Benegal 2012). Two contrasting items on expected sea level rise due to climate change were either overly optimistic (not more than $10 \mathrm{~cm}$ during the next 20 years) or fairly realistic (more than $10 \mathrm{~cm}$ during the next 20 years) representations of IPCC figures (IPCC 2007). After reverse coding of one item, Cronbach's alpha of the three-item scale was .73. Perceived outside-the-dikes risk was measured by the items "Because of climate change harbor areas outside the dikes will be flooded more frequently and at greater depth." and "Due to climate change and flood risks, the value of the dwellings outside the dikes will decrease in the future." The intercorrelation between the two items was sufficiently high $(r=.48$, $p<.001, n=1887)$ to justify combining them into a scale. Among all participants, skepticism about climate change and perceived outside-the-dikes risk were moderately negatively correlated $(r=-.36, p<.001$, $n=1887)$.

\section{Statistical analysis}

Four $t$ tests, with Levene's test for equality of variances, were applied to determine whether there were any differences between the responses of the control group and the framed groups on the variables. Cohen's $d$ was used for determination of effect sizes. Focusing on the framed groups to test our expectation, we carried out a multivariate 2 (focal context) $\times 2$ (future direction) analysis of variance with the four dependent variables, using Pillai's trace test statistic as the criterion. Bonferroni correction ( $p=.05$ ) was used for multiple comparisons. The variables gender, age, household size, level of education and residential location were potential covariates. This was followed by univariate tests and correlation analyses to gain a deeper understanding of the impacts on each of the dependent variables. SPSS 21 was used for all calculations.

\section{Results}

The responses of the control group provided a reference level for comparison with the participants of the framed groups. Homogeneity of variance was verified with Levene's test for equality of variances, and it did not differ across the groups. The $t$ tests revealed that the framed groups had a much higher level of prevention-focused responses $(M=4.83, S D=1.22)$ than the control group $(M=2.77, \quad S D=1.26, \quad t(1885)=22.20, \quad$ Cohen's $d=1.30, p<.001)$ as well as a slightly lower level of promotion-focused responses $(M=3.91, S D=1.18$, and $M=4.24, S D=1.20, t(1885)=3.71, d=.28, p<.001)$. The framed groups also had a slightly lower level of skepticism about climate change $(M=4.01, S D=1.22$, and $M=4.21, S D=1.23, t(1885)=2.20, d=.16$, $p<.05$, not significant after Bonferroni correction) and a somewhat higher level of perceived outside-the-dikes risk $(M=4.43, \quad S D=1.08, \quad$ and $\quad M=4.18, \quad S D=1.13$, $t(1885)=2.98, d=.23, p<.01)$.

Using only the framed groups, we carried out a multivariate 2 (focal context) x 2 (future direction) analysis of variance with the four dependent variables. In a preliminary analysis, the variables gender, age, household size, level of education and residential location were investigated as potential covariates, but all except age were nonsignificant and eliminated from the analysis. The multivariate tests showed significant main effects for focal context (multivariate $F(4,1674)=9.35, \quad \eta^{2}=.022$, $p<.001$ ), future direction (multivariate $F(4,1674)=$ 5.44, $\eta^{2}=.013, p<.001$ ) and age (multivariate $F(4$, $\left.1674)=9.87, \eta^{2}=.023, p<.001\right)$. The Context $\times \mathrm{Fu}-$ ture interaction was also significant, but very small (multivariate $\left.F(4,1674)=2.87, \eta^{2}=.007, p<.05\right)$. The mean and standard deviation scores of the variables and the results of the univariate tests are presented in Table 1 . Regarding the main effects of focal context, the univariate statistics show that the "living outside the dikes" frames (frames 1 and 2) resulted in a higher level of preventionfocused responses. Frame 1 ("living outside the dikes" and "changing climate") also lead to a somewhat higher level of perceived outside-the-dikes risk and a slightly lower level of promotion-focused responses. The latter effect accounted for the significant interaction term Context $\times$ Future. Skepticism about climate change was the only variable that did not differ between the groups. The significant effect of age was based on two weak positive correlations with skepticism about climate change $(r=.07, p<.01)$ and perceived outside-the-dikes risk $(r=.09, p<.001)$, which were themselves negatively correlated $(r=-.36, p<.001)$. Overall, the differences 
Table 1 Comparison of the framed groups for the four variables: mean and standard deviation scores (parenthesis) and ANOVA results

\begin{tabular}{|c|c|c|c|c|c|}
\hline & $\begin{array}{l}\text { Frame } 1 \\
(n=423)\end{array}$ & $\begin{array}{l}\text { Frame } 2 \\
(n=414)\end{array}$ & $\begin{array}{l}\text { Frame } 3 \\
(n=433)\end{array}$ & $\begin{array}{l}\text { Frame } 4 \\
(n=412)\end{array}$ & $\begin{array}{l}\text { ANOVA results } \\
(d f 3,1678)\end{array}$ \\
\hline Prevention-focused responses & $\begin{array}{l}5.05^{\mathrm{a}} \\
(1.30)\end{array}$ & $\begin{array}{l}4.94^{\mathrm{ab}} \\
(1.19)\end{array}$ & $\begin{array}{l}4.76^{\mathrm{bc}} \\
(1.26)\end{array}$ & $\begin{array}{l}4.55^{\mathrm{c}} \\
(1.22)\end{array}$ & $F=12.72, p<.001$ \\
\hline Promotion-focused responses & $\begin{array}{l}3.73^{\mathrm{a}} \\
(1.24)\end{array}$ & $\begin{array}{l}4.05^{\mathrm{b}} \\
(1.19)\end{array}$ & $\begin{array}{l}3.90^{\mathrm{ab}} \\
(1.14)\end{array}$ & $\begin{array}{l}3.96^{\mathrm{b}} \\
(1.14)\end{array}$ & $F=5.41, p<.01$ \\
\hline Skepticism about climate change & $\begin{array}{l}3.97^{\mathrm{a}} \\
(1.20)\end{array}$ & $\begin{array}{l}3.93^{\mathrm{a}} \\
(1.20)\end{array}$ & $\begin{array}{l}4.00^{\mathrm{a}} \\
(1.20)\end{array}$ & $\begin{array}{l}4.13^{\mathrm{a}} \\
(1.20)\end{array}$ & $F=2.11, p>.05$ \\
\hline Perceived outside-the-dikes risk & $\begin{array}{l}4.64 \\
(1.07)\end{array}$ & $\begin{array}{l}4.41^{\mathrm{a}} \\
(1.09)\end{array}$ & $\begin{array}{l}4.37^{\mathrm{a}} \\
(1.07)\end{array}$ & $\begin{array}{l}4.26^{\mathrm{a}} \\
(1.06)\end{array}$ & $F=9.07, p<.001$ \\
\hline
\end{tabular}

Means that have no superscript in common are significantly different from each other (Bonferroni test, $p<.05$ )

between the conditions were small, but they agreed with the expected pattern.

Among the participants in the "outside the dikes" condition (frames 1 and 2), prevention-focused responses and perceived outside-the-dikes risk were correlated positively $r=.38(n=835, p<.001)$. By comparison, this correlation was only $r=.16(n=843, p<.001)$ in the "deep polder" conditions (frames 3 and 4$)$ and $r=.12(n=205$, $p>.05)$ in the control group. In the same groups, climate change skepticism correlated negatively with perceived outside-the-dikes risk $(r=-.36, r=-.34$, and $r=-.35$, all $p \mathrm{~s}<.001)$ and prevention-focused responses $(r=-.18, r=-.13$, and $r=-.23$, all $p$ s $<.01)$. Finally, the main analyses were repeated separately for the participants with relatively low, medium and high scores on climate change skepticism (i.e., the lowest, middle and highest triad). The impact of the risk frames on preventionfocused responses was relatively stable among the three segments $(F(3,497)=4.36, F(3,665)=4.69$ and $F(3$, $508)=3.69$, all $p \mathrm{~s}<.05$ ); the correlation between prevention-focused responses and perceived outside-the-dikes risk decreased $(r=.37, \quad r=.24$ and $r=.16$, all $p \mathrm{~s}<.001$ ) with increasing skepticism.

\section{Discussion}

The results of the experiment can be meaningfully interpreted in terms of motivational influences on information processing. The risk frames provided the participants with relevant and diagnostic information about climate-related flood risks (framed groups versus control group). The most relevant diagnostic information (frame 1, increasing risk outside the dikes) resulted in the highest levels of prevention-focused responses and perceived outside-the-dikes risk. In the "outside the dikes" condition (frames 1 and 2), there was a positive correlation between prevention-focused responses and perceived outside-the-dikes risk, and this correlation was highly specific to this condition (i.e., showing the increased impact of motivation to know "what is real"). In all the conditions, climate change skepticism had negative correlations with perceived outside-the-dikes risk and to a lesser degree with prevention-focused responses (i.e., reflecting a motivation-based trade-off). The main results of the experiment were not different among participants with relatively low, medium or high levels of skepticism, except for the correlation between preventionfocused responses and perceived outside-the-dikes risk, which decreased with increasing skepticism (i.e., also reflecting a motivation-based trade-off). The main results of the experiment were not dependent on the variables gender, age, household size, level of education and residential location, which would imply a potential limitation in the generalizability of our study to contexts where these variables are different from our case study area. In sum, these results indicate that it was possible to increase the participants' local climate risk perception in combination with increased motivation for flood damage prevention, despite a certain level of climate change skepticism.

An important contribution of the study is the empirical and theoretical evidence on how climate change and flood risk communication may benefit from insights into conditions that facilitate vigilant and careful information processing and conditions that evoke the need to maintain prior beliefs (Darke and Chaiken 2005; Hart et al. 2009; Kunda 1990; Molden and Higgins 2005). Although our data do not explicitly show to what extent information processing was guided by particular motivations, the results indicate that prevention concerns and climate change skepticism played opposing roles in shaping the participants' responses to the risk frames. Importantly, the risk frames did not lead to a higher level of climate skepticism or to a higher level of variance in the data. It should be noted that the background and the impact of climate skepticism may significantly vary between countries and over time and that there are grades of skepticism (Poortinga et al. 2011; Scruggs and Benegal 2012). In our sample, the number of "science deniers" and believers in conspiracy 
theories (Lewandowsky et al. 2013; Scannell and Gifford 2013) might have been too small to give more extreme results. Many less extreme climate change skeptics may in fact be sensitive to conditions that facilitate vigilant and careful information processing when a prevention focus is activated in the situation.

A key feature of our approach was that climate change was not addressed in isolation but in the context of geographic variations in the occurrence of flood risks, which were relevant for people's concerns. This approach is in line with earlier research on ways to make climate change information more personally relevant (de Boer et al. 2010; Leiserowitz 2007; Myers et al. 2013; Scannell and Gifford 2013; Spence et al. 2012). For instance, Leiserowitz (2007) made a plea for efforts to make global climate change local and to highlight its potential connections with extreme weather events, while being careful to respect current levels of scientific understanding. Using an approach that is partially similar to ours, Evans et al. (2014) asked a group of residents in the Wellington region of New Zealand to answer questions about potential local sea level rise and adaptation measures that could be taken in their region. After this attempt to make the problem of climate change less distant and more tangible, the group showed an increased willingness to perform personal emissions-reducing behaviors in comparison with a control group. In addition to this, our study demonstrates that personal relevance is not simply a general factor but that it can be further differentiated in terms of more focused motives. When people are prevention focused, they are sensitive to and guided by safety, security and protection needs (Higgins 1997, 2000, 2012). As the responses to the risk frames demonstrate, this type of motivation may effectively help to reduce the psychological distance of climate change and to make information on its potential impacts more relevant and diagnostic.

Our study gave relatively less attention to promotion motivation, and as expected, it was not a dominant factor in the responses to the risk frames. In the context of risks and disasters, many people will focus on prevention motives, although this can be different when the loss has already occurred and risk seeking may become a necessity (Scholer et al. 2010). Our measure of promotion-focused responses suggested that people who responded to the risk frames with a promotion focus tended to look at the amenities of the water-abundant environment (i.e., this item got the highest mean of all items measuring promotion-oriented responses). This outcome does not come as a surprise, as the historical interaction between the Netherlands and the sea has led to the development, over time, of successful human interventions (VanKoningsveld et al. 2008), which have reduced the inhabitants' experience with flood hazards and their perception of flood likelihood (Terpstra
2011). However, for more than just prevention-oriented communication on climate proofing, it is important to develop strategies that fit a promotion focus. A novel option to consider is that the steps necessary for climate proofing may be divided into prevention-related aspects, such as buying insurance, and promotion-related aspects, such as investing in measures that increase property values. In this way, policy makers may create the conditions where prevention- and promotion-focused individuals can productively work together. This coordinated approach will become increasingly important as policy makers in the Netherlands seek to make the private sector to some extent responsible for covering their own flood risk (Botzen and van den Bergh 2012; Husby et al. 2015).

One of the limitations of the study is that the participants were asked to respond as if they themselves lived in a neighborhood that was vulnerable to flood risks. This was necessary because we were not in the position to inform them about flood risks associated with their own dwellings. As a result, the role of typical local variables, such as place attachment (Scannell and Gifford 2013) or homeownership (Parker et al. 2009), could not be assessed. Further research should pay more attention to these variables, because prevention-focused concerns fit very well with place-protective or identity-preserving behavior. Another aspect of the design was that the climate change skepticism was measured after the experimental manipulation (i.e., to avoid sensitizing effects). Climate change skepticism appeared slightly lower in the experimental groups, but it was not possible to assess whether this difference was due to an effect of the experiment. In addition, it should be noted that the information presented in the risk frames may have influenced the results in several ways. For instance, the photographs used to visualize the notion of floor flooding show individuals being affected by water on the street, whereas the other frames do not feature any people. This may have influenced the prevention-focused responses more than the other information. It should also be emphasized that all the information presented in the risk frames was based on realistic pictures and figures, such as a 1-in-10-year probability of floor flooding and a 1-in-2000year probability of deep flooding. This approach, which constrained the options for message variations, may explain why the differences between the responses to the four risk frames were relatively small.

\section{Conclusions}

Our study underlines that it makes sense to identify areas of synergy or conflict in relation to climate change and flood risk communication, as these topics may have different motivational influences on information processing, 
resulting in an implicit trade-off between motivation to know "what is real" and motivation to maintain prior beliefs. Flood-related prevention concerns and climate change skepticism played opposing roles in shaping the participants' local climate risk perception. Prevention concerns were much more prominent in the framed groups than in the control group, which also had an effect on the perceived climate-related risk in the area outside the dikes. This means that the very nature of prevention-focused motivation and its emphasis on vigilant and careful information processing can fruitfully be used in the development of plans to communicate information about flood risk. It means also that climate change information should not be addressed in isolation but as part of coherent risk stories, for instance, by putting the risk issue in a broader perspective (e.g., climate change and spatial planning) and zooming-in on particular details (e.g., geographic variations in the occurrence and potential impact of flood risks). In this way, climate change and flood risk communication can be well framed from the perspective of how motivation works, stimulating citizens' need to know "what's real" and to take responsibility for preparedness.

Acknowledgments This paper is based on work funded by the Knowledge for Climate (KfC) Research Program for the development of knowledge and services that make it possible to climate proof the Netherlands (Grant Number HSRR07/HSGR08). W.J.W. Botzen received additional financial support from the Netherlands Organization for Scientific Research (NWO). All authors contributed to conception and design of the study. The first author has been responsible for the analysis and the reporting of the results of the communication experiment. We are very grateful to the anonymous reviewers for their valuable comments.

\section{Compliance with ethical standards}

Conflict of interest The authors report no conflicts of interest.

Ethical standard All the participants were volunteers who participated in web-based research administered by the Dutch survey agency TNS NIPO (part of the worldwide Taylor Nelson Sofres Group), which provided the data to the authors, subject to the requirements of the ESOMAR Code of Conduct to respect the anonymity of respondents.

Open Access This article is distributed under the terms of the Creative Commons Attribution 4.0 International License (http://crea tivecommons.org/licenses/by/4.0/), which permits unrestricted use, distribution, and reproduction in any medium, provided you give appropriate credit to the original author(s) and the source, provide a link to the Creative Commons license, and indicate if changes were made.

\section{References}

Barsalou LW (1992) Abstraction as dynamic interpretation in perceptual symbol systems. In: Gershkoff-Stowe L, Rakison D (eds) Building object categories. Erlbaum, Carnegie Symposium Series, Majwah, pp 389-431

Bednarek MA (2005) Frames revisited-the coherence-inducing function of frames. J Pragmat 37:685-705. doi:10.1016/j. pragma.2004.09.007

Berkhout F, Van den Hurk B, Bessembinder J, de Boer J, Bregman B, van Drunen M (2014) Framing climate uncertainty: socioeconomic and climate scenarios in vulnerability and adaptation assessments. Reg Environ Change 14:879-893. doi:10.1007/ s10113-013-0519-2

Botzen WJW, van den Bergh JCJM (2012) Monetary valuation of insurance against flood risk under climate change. Int Econ Rev 53:1005-1026. doi:10.1111/j.1468-2354.2012.00709.x

Botzen WJW, Aerts JCJH, van den Bergh JCJM (2009) Dependence of flood risk perceptions on socio-economic and objective risk factors. Water Resour Res 45:W10440. doi:10.1029/2009 WR007743

Botzen WJW, de Boer J, Terpstra T (2013) Framing of risk and preferences for annual and multi-year flood insurance. J Econ Psychol 39:357-375. doi:10.1016/j.joep.2013.05.007

Corner A, Whitmarsh L, Xenias D (2012) Uncertainty, scepticism and attitudes towards climate change: biased assimilation and attitude polarisation. Clim Change 114:463-478. doi:10.1007/ s10584-012-0424-6

Darke PR, Chaiken S (2005) The pursuit of self-interest: self-interest bias in attitude judgment and persuasion. J Pers Soc Psychol 89:864-883. doi:10.1037/0022-3514.89.6.864

de Boer J, Wardekker JA, van der Sluijs JP (2010) Frame-based guide to situated decision-making on climate change. Glob Environ Chang 20:502-510. doi:10.1016/j.gloenvcha.2010.03.003

de Boer J, Schösler H, Boersema JJ (2013) Climate change and meat eating: an inconvenient couple? J Environ Psychol 33:1-8. doi:10.1016/j.jenvp.2012.09.001

de Boer J, Botzen WJW, Terpstra T (2014) Improving flood risk communication by focusing on prevention-focused motivation. Risk Anal 28:309-322. doi:10.1111/risa.12091

de Boer J, Botzen WJW, Terpstra T (2015) More than fear induction: toward an understanding of people's motivation to be wellprepared for emergencies in flood prone areas. Risk Anal 35:518-535. doi:10.1111/risa.12289

de Bruin WB, Wong-Parodi G, Morgan MG (2014) Public perceptions of local flood risk and the role of climate change. Environ Syst and Decis 34:591-599. doi:10.1007/s10669-014-9513-6

Dempsey R, Fisher A (2005) Consortium for Atlantic Regional Assessment: information tools for community adaptation to changes in climate or land use. Risk Anal 25:1495-1509. doi:10. 1111/j.1539-6924.2005.00695.x

Evans L, Milfont TL, Lawrence J (2014) Considering local adaptation increases willingness to mitigate. Glob Environ Chang 25:69-75. doi:10.1016/j.gloenvcha.2013.12.013

Fillmore CF, Atkins BT (1992) Toward a frame-based lexicon: the semantics of RISK and its neighbors. In: Lehrer A, Kittay EF (eds) Frames, fields, and contrasts: new essays in semantic and lexical organization. Lawrence Erlbaum Associates, Hillsdale, pp 75-102

Fischhoff B (2007) Nonpersuasive communication about matters of greatest urgency: climate change. Environ Sci Technol 41:7204-7208. doi:10.1021/es0726411

Grothmann T, Reusswig F (2006) People at risk of flooding: why some residents take precautionary action while others do not. Nat Hazards 38:101-120. doi:10.1007/s11069-005-8604-6

Hart PS, Nisbet EC (2012) Boomerang effects in science communication: how motivated reasoning and identity cues amplify opinion polarization about climate mitigation policies. Commun Res 39:701-723. doi:10.1177/0093650211416646 
Hart W, Albarracín D, Eagly AH, Brechan I, Lindberg MJ, Merrill L (2009) Feeling validated versus being correct: a meta-analysis of selective exposure to information. Psychol Bull 135:555-588. doi: $10.1037 / \mathrm{a} 0015701$

Harvatt J, Petts J, Chilvers J (2011) Understanding householder responses to natural hazards: flooding and sea-level rise comparisons. J Risk Res 14:63-83. doi:10.1080/13669877.2010. 503935

Heath Y, Gifford R (2006) Free-market ideology and environmental degradation: the case of beliefs in global climate change. Environ Behav 38:48-71. doi:10.1177/0013916505277998

Higgins ET (1997) Beyond pleasure and pain. Am Psychol 52:1280-1300. doi:10.1037/0003-066X.52.12.1280

Higgins ET (2000) Making a good decision: value from fit. Am Psychol 55:1217-1230. doi:10.1037/0003-066X.55.11.1217

Higgins ET (2012) Beyond pleasure and pain: how motivation works. Oxford University Press, New York

Husby TG, Mechler R, Jongman B (2015) What if Dutch investors started worrying about flood risk? Implications for disaster risk reduction. Reg Environ Change. doi:10.1007/s10113-015-0769-2

IPCC (2007) Summary for policymakers. In: Solomon S, Qin D, Manning M, Chen Z, Marquis M, Averyt KB, Tignor M, Miller HL (eds) Climate change 2007: The physical science basis. Contribution of working group I to the fourth assessment report of the intergovernmental panel on climate change. Cambridge University Press, Cambridge, UK, pp 1-18

Johnson BT, Eagly AH (1989) Effects of involvement on persuasion-a meta-analysis. Psychol Bull 106:290-314. doi:10.1037// 0033-2909.106.2.290

Jongman B, Ward PJ, Aerts JCJH (2012) Global exposure to river and coastal flooding: long term trends and changes. Glob Environ Chang 22:823-835. doi:10.1016/j.gloenvcha.2012.07.004

Kabat P, van Vierssen W, Veraart J, Vellinga P, Aerts J (2005) Climate proofing the Netherlands. Nature 438:283-284. doi:10. 1038/438283a

Kahan DM, Jenkins-Smith H, Braman D (2011) Cultural cognition of scientific consensus. J Risk Res 14:147-174. doi:10.1080/ 13669877.2010.511246

Kokx A, Spit $T$ (2012) Increasing the adaptive capacity in unembanked neighborhoods? An exploration into stakeholder support for adaptive measures in Rotterdam, the Netherlands. Am J Clim Change 1:181-193. doi:10.4236/ajcc.2012

Kreibich H, Thieken AH, Petrow T, Müller M, Merz B (2005) Flood loss reduction of private households due to building precautionary measures: lessons learned from the Elbe flood in August 2002. Nat Hazard Earth Syst Sci 5:117-126

Kreibich H, Seifert I, Thieken AH, Lindquist E, Wagner K, Merz B (2011) Recent changes in flood preparedness of private households and businesses in Germany. Reg Environ Change 11:59-71. doi:10.1007/s10113-010-0119-3

Kunda Z (1990) The case for motivated reasoning. Psychol Bull 108:480-498. doi:10.1037//0033-2909.108.3.480

Leiserowitz AA (2005) American risk perceptions: is climate change dangerous? Risk Anal 25:1433-1442. doi:10.1111/j.1540-6261. 2005.00690.x

Leiserowitz AA (2007) Communicating the risks of global warming: American risk perceptions, affective images, and interpretive communities. In: Moser SC, Dilling L (eds) Creating a climate for change: communicating climate change and facilitating social change. Cambridge University Press, New York, pp 44-63

Lewandowsky S, Gignac GE, Oberauer K (2013) The role of conspiracist ideation and worldviews in predicting rejection of science. PLoS ONE 8:e75637. doi:10.1371/journal.pone.0075637

Molden DC, Higgins ET (2005) Motivated thinking. In: Holyoak KJ, Morrison RG (eds) The Cambridge handbook of thinking and reasoning. Cambridge University Press, New York, pp 295-317
Moser SC (2010) Communicating climate change: history, challenges, process and future directions. WIREs Clim Change 1:31-53. doi:10.1002/wcc.011

Myers TA, Maibach EW, Roser-Renouf C, Akerlof K, Leiserowitz AA (2013) The relationship between personal experience and belief in the reality of global warming. Nat Clim Chang 3:343-347. doi:10.1038/NCLIMATE1754

O'Neill SJ, Boykoff M, Niemeyer S, Day SA (2013) On the use of imagery for climate change engagement. Glob Environ Chang 23:413-421. doi:10.1016/j.gloenvcha.2012.11.006

Parker DJ, Priest SJ, Tapsell SM (2009) Understanding and enhancing the public's behavioural response to flood warning information. Meteorol Appl 16:103-114. doi:10.1002/met.119

Poortinga W, Spence A, Whitmarsh L, Capstick S, Pidgeon NF (2011) Uncertain climate: an investigation into public scepticism about anthropogenic climate change. Glob Environ Chang 21:1015-1024. doi:10.1016/j.gloenvcha.2011.03.001

Ruddell D, Harlan SL, Grossman-Clarke S, Chowell G (2012) Scales of perception: public awareness of regional and neighborhood climates. Clim Change 111:581-607. doi:10.1007/s10584-0110165-y

Scannell L, Gifford R (2013) Personally relevant climate change: the role of place attachment and local versus global message framing in engagement. Environ Behav 45:60-85. doi:10.1177/ 0013916511421196

Scholer AA, Zou X, Fujita K, Stroessner SJ, Higgins ET (2010) When risk seeking becomes a motivational necessity. J Pers Soc Psychol 99:215-231. doi:10.1037/a0019715

Scruggs L, Benegal S (2012) Declining public concern about climate change: can we blame the great recession? Glob Environ Chang 22:505-515. doi:10.1016/j.gloenvcha.2012.01.002

Siegrist M, Gutscher H (2006) Flooding risks: a comparison of lay people's perceptions and expert's assessments in Switzerland. Risk Anal 26:971-979. doi:10.1111/j.1539-6924.2006.00792.x

Smit B, Wandel J (2006) Adaptation, adaptive capacity and vulnerability. Glob Environ Chang 16:282-292. doi:10.1016/j.gloenv cha.2006.03.008

Spence A, Poortinga W, Pidgeon N (2012) The psychological distance of climate change. Risk Anal 32:957-972. doi:10. 1111/j.1539-6924.2011.01695.x

Terpstra T (2011) Emotions, trust, and perceived risk: affective and cognitive routes to flood preparedness behavior. Risk Anal 31:1658-1675. doi:10.1111/j.1539-6924.2011.01616.x

Terpstra T, Lindell MK (2013) Citizens' perceptions of flood hazard adjustments: an application of the Protective Action Decision Model. Environ Behav 45:993-1018. doi:10.1177/00139165 12452427

Terpstra T, Zaalberg R, de Boer J, Botzen WJW (2014) You have been framed! How antecedents of information need mediate the effects of risk communication messages. Risk Anal 34:1506-1520. doi:10.1111/risa.12181

VanKoningsveld M, Mulder JPM, Stive MJF, VanDerValk L, VanDerWeck AW (2008) Living with sea-level rise and climate change: a case study of the Netherlands. J Coast Res 24:367-379. doi:10.2112/07A-0010.1

Whitmarsh L (2008) Are flood victims more concerned about climate change than other people? The role of direct experience in risk perception and behavioural response. J Risk Res 11:351-374. doi:10.1080/13669870701552235

Whitmarsh L (2011) Scepticism and uncertainty about climate change: dimensions, determinants and change over time. Glob Environ Chang 21:690-700. doi:10.1016/j.gloenvcha.2011.01. 016

Zhou RR, Pham MT (2004) Promotion and prevention across mental accounts: when financial products dictate consumers' investment goals. J Consum Res 31:125-135. doi:10.1086/383429 